\title{
PERANCANGAN SISTEM PENUNJANG KEPUTUSAN PENILAIAN KINERJA KARYAWAN DENGAN METODE AHP PT GDSK
}

\author{
Riska Nur Azizah ${ }^{1}$, Irwan Agus ${ }^{2}$, Rahnita Nuzulah ${ }^{3}$ \\ 1,2,3 Program Studi Teknik Informatika, Fakultas Teknik dan Ilmu Komputer, \\ Universitas Indraprasta PGRI \\ Jalan Raya Tengah No 80, Kelurahan Gedong, Pasar Rebo, Jakarta Timur \\ riskanurazizah08@gmail.com ${ }^{1}$, irwan.agus08@yahoo.com² ${ }^{2}$ rahnita21@gmail.com ${ }^{3}$
}

\begin{abstract}
Abstrak
Tujuan dari penelitian ini adalah untuk merancang dan mengimplementasikan serta mendapatkan laporan yang efisien dan akurat sehingga dengan adanya sistem penunjang keputusan tidak memungkinkan terjadinya duplikasi data dan kesalahan input. Metodologi penelitian yang digunakan dalam sistem pengolahan data yaitu teknik pengumpulan data seperti obesrvasi, studi dokumentasi, serta melakukan penelitian kepustakaan yang relevan dengan masalah sistem penunjang keputusan penilaian kinerja karyawan sebelumnya. Metode pengembangan sistem yang digunakan adalah metode AHP (Analytical Hierarchy Process). Hasil penelitian yang dibuat oleh peneliti ini sangat membantu untuk memberikan kelancaran dalam pengolahan sistem penunjang keputusan penilaian kinerja karyawan di PT Gobel Dharma sarana Karya.
\end{abstract}

Kata Kunci: Penilaian Kinerja Karyawan, AHP, Sistem Penunjang Keputusan

\begin{abstract}
The purpose of this research is to design and implement and obtain efficient and accurate reports so that the decision support system does not allow duplication of data and input errors. The research methodology used in the data processing system is data collection techniques such as observation, documentation study, as well as conducting library research that is relevant to the decision support system problems for previous employee performance appraisals. The system development method used is the AHP (Analytical Hierarchy Process) method. The results of the research made by this researcher are very helpful in providing smooth processing of the decision support system for employee performance appraisals at PT Gobel Dharma Sarana Karya.
\end{abstract}

Keyword: Employee Performance Appraisal, AHP, The Decision Support System

\section{PENDAHULUAN}

Perkembangan teknologi komputer yang semakin pesat di zaman sekarang semakin banyak memberikan manfaat dalam kehidupan manusia. Kemajuan ilmu pengetahuan saat ini ditandai dengan banyaknya perkembangan teknologi sehingga banyak dihasilkan alat-alat canggih dan mutakhir. Perancangan adalah penggambaran, perencanaan, dan pembuatan sketsa atau pengaturan dari beberapa elemen yang terpisah ke dalam satu kesatuan yang utuh dan berfungsi. Perancangan menggambarkan rencana umum suatu kegiatan rancangan proyek dan aktivitas-aktivitas khusus yaitu teknik atau metode-metode dalam merancang sesuatu [1]. Sistem adalah kumpulan atau group dari sub sistem atau bagiang atau komponen apapun baik phisik ataupun non phisik yang saling berhubungan satu sama lain dan bekerja sama secara harmonis untuk mencapai satu tujuan tertentu [2]. Sistem dapat diartikan sebagai suatu kumpulan atau himpunan dari unsur komponen atau variabel-variabel yang terorganisasi yang saling berinteraksi, saling bergantungan satu sama lain [3]. Sistem Pendukung Keputusan (SPK) adalah suatu sistem berbasis komputer yang menghasilkan berbagai alternatif keputusan untuk membantu manajemen dalam menangani berbagai permasalahan yang terstruktur ataupun tidak terstruktur dengan menggunakan data dan model. Tujuan adanya Sistem Pendukung Keputusan, untuk mendukung pengambilan keputusan memilih alternatif hasil pengolahan informasi dengan model-model pengambil keputusan serta menyelesaikan masalah yang bersifat semi terstruktur dan tidak terstruktur. Data atau model yang digunakan yaitu karyawan dengan informasi berupa penilaian kinerja. Penilaian kinerja merupakan 
proses yang dilakukan dalam mengevaluasi kinerja pekerjaan seseorang. Penilaian kinerja meliputi dimensi kinerja karyawan, dan akuntabilitas [4].

Diagram Alir Data adalah suatu diagram yang menggunakan notasi-notasi untuk menggambarkan arus dari data sistem yang penggunaannya sangat membantu untuk memahami sistem secara logika, terstruktur, dan jelas [1]. Diagram Alir Data merupakan alat pembuatan model yang memungkinkan professional sistem untuk menggambarkan sistem sebagai suatu jaringan proses fungsional yang menghubungkan satu sama lain dengan alur data baik secara manual ataupun secara terkomputerisasi [5]. Diagram Alir Data adalah referesentasi grafik yang menggambarkan aliran informasi dan trasnformasi informasi yang diaplikasikan sebagai data yang mengatur dari masukan (input) dan keluaran (output). DAD tidak sesuai untuk memodelkan sistem yang menggunakan pemrograman berorientasi objek [6].

Situasi PT Gobel Dharma Sarana Karya (GDSK) yang semakin membutuhkan pelayanan yang baik menyebabkan perusahaan melakukan langkah-langkah konkrit yaitu dengan melakukan penilaian kinerja karyawan adalah dengan menggunakan suatu alat yang dinamakan Performance Appraisal (penilaian kinerja) agar menunjang semua kebutuhan pelayanan yang baik terhadap klien. PT GDSK dalam penilaian kinerja karyawan masih menggunakan cara manual sehingga menyebabkan terhambatnya penyusunan data karena membutuhkan waktu yang lama, dan masih sering terjadi kesalahan sehingga membuat data tidak akurat. Manfaat dari penelitian ini adalah untuk menghasilkan informasi yang akurat dan adil dalam pengambilan keputusan, untuk mengimplementasi dan mempermudah dalam mengolah data guna membantu mengatasi proses penilaian kinerja karyawan di PT GDSK yang masih manual menjadi terkomputerisasi.

\section{PENELITIAN RELEVAN}

Penelitian jurnal Semnasteknomedia Online ISSN : 2302-3805 oleh Heri Nurdiyanto dan Heryanita Meilia yang berjudul Sistem Pendukung Keputusan Penentuan Prioritas Pengembangan Industri Kecil Dan Menengah Di Lampung Tengah Menggunakan Metode AHP tahun 2016. Hasil dari penelitian ini adalah untuk menyeleksi IKM yang sesuai untuk mengembangkan industri tersebut. Penelitian ini menjadi acuan penulis karena menggunakan metode AHP dan juga mengambil keputusan dengan penentuan prioritas dimana penulis mengambil keputusan dengan penilaian kinerja yang didalamnya menggunakan ketentuan nilai bobot kriteria yang relevan untuk menilai kinerja karyawan [7].

Penelitian Jurnal Teknologi dan Sistem Komputer e-ISSN : 2338-0403 oleh Desi Ratna Sari yang berjudul Sistem Pendukung Keputusan Untuk Rekomendasi Kelulusan Sidang Skripsi Menggunakan Metode AHP-TOPSIS tahun 2018. Hasil dari penelitian ini adalah untuk merancang suatu sistem pendukung keputusan penentuan kelulusan siding skripsi yang dapat membantu Universitas dalam memilih mahasiswa/I yang tepat dan akurat. Penelitian ini juga menjadi acuan penulis karena menggunakan gagasan rekomendasi kelulusan dimana penulis juga menggunakan penilaian kinerja guna mendapatkan rekomendasi karyawan yang terbaik selama bekerja di PT GDSK [8].

\section{METODE PENELITIAN}

\section{Metode Pengumpulan Data}

Perancangan Sistem adalah sekumpulan aktivitas yang menggambarkan secara rinci bagaimana sistem akan berjalan (Jackson, 2012). Metode pengumpulan data yang dilakukan oleh penulis untuk mendapatkan data-data serta informasi untuk mendukung penyempurnaan hasil dari penelitian ini antara lain :

\section{Studi Lapangan}

a. Observasi

Peneliti mengamati secara langsung mengenai objek dan penelitian yang sedang diamati, tepatnya dimulai pada bulan April 2020 sampai dengan bulan Juli 2020. 
b. Wawancara

Pengumpulan data dengan wawancara ini dilakukan untuk mencari data dan informasi tentang hal-hal yang dibutuhkan dalam penelitian. Wawancara dilakukan di lingkungan PT GDSK.

c. Pemilihan Sampel

Sampel adalah bagian-bagian dari populasi yang dipilih sebagai wakil representatif dari keseluruhan untuk diteliti. Dalam penelitian ini metode pemilihan sampel yang digunakan adalah Teknik purposive sampling. Seseorang atau sesuatu diambil sebagai sampel karena peneliti menanggap bahwa seseorang atau sesuatu tersebut memiliki informasi yang diperlukan bagi peneliti.

\section{Kepustakaan}

Metode ini untuk pengumpulan data dengan cara mempelajari beberapa buku, sarana perpustakaan dan catatan-catatan kuliah yang berhubungan dengan yang diajukan. Peneliti membaca buku, artikel ilmiah dan jurnal yang terkait dengan sistem penunjang keputusan penilaian kinerja karyawan, metode Analytical Hierarcy Process (AHP) dan peneliti mendatangi perpustakaan Universitas Indraprasta untuk melihat dan membaca skripsi yang terkait dengan sistem pendukung keputusan pemilihan karyawan terbaik.

\section{AHP (Analytical Hierarchy Proces)}

Metode ini adalah kerangka untuk mengambil keputusan dengan efektif atas persoalan yang kompleks dengan menyederhanakan dan mempercepat proses pengambil keputusan dengan memecahkan persoalan tersebut ke dalam bagian-bagiannya, menata bagian atau variabel dan mensitensis berbagai pertimbangan ini untuk mempengaruhi hasil pada situasi tersebut.

Adapun langkah-langkah dalam menggunakan metode AHP untuk pemecahan suatu masalah sebagai berikut :

1. Mendefinisikan masalah dan menentukan solusi yang diinginkan, lalu menyusun hierarki dari permasalahan yang dihadapi.

2. Menentukan prioritas elemen

Menentukan kriteria : absensi, kerapihan, performa kinerja, dan kedisiplinan

Menentukan subkriteria : sangat baik : 100, baik : 75, rata-rata : 50, dan cukup : 25

3. Sintesis

Menentukan nilai perbandingan berpasangan, tingkat kepentingan satu kriteria dibandingkan dengan yang lain.

4. Mengukur Konsistensi

Kemudian menentukan matriks normalisasi dengan cara pembagian antara nilai tiap sel dengan nilai jumlah sesuai kolom.

5. Hitung Indeks Konsistensi dengan rumus :

$$
\mathrm{CI}=\frac{\lambda \text { maks }-\mathrm{n}}{\mathrm{n}-1}
$$

6. Hitung Rasio Konsistensi dengan rumus :

$$
(\mathrm{CR})=\frac{\mathrm{CI}}{\mathrm{IR}}
$$

7. Memeriksa konsistensi hirarki

Terakhir adalah menentukan rangking dari alternatif dengan cara menghitung eigen vector untuk tiap kirteria dan sub kriteria. 


\section{HASIL DAN PEMBAHASAN}

\section{Analisis Permasalahan}

Setelah menganalisa sistem berjalan, maka peneliti menyimpulkan bahwa untuk mempermudah seluruh aktivitas pengambilan keputusan penilaian kinerja karyawan, selama ini perusahaan masih menggunakan dokumen. Hal ini mendorong peneliti untuk mencoba mengembangkan rancangan penilaian kinerja karyawan berbasis java di PT Gobel Dharma Sarana Karya.

Berikut uraian dari penyelesaian masalah yang diharapkan.

1. PT Gobel Dharma Sarana Karya sebaiknya membuat suatu aplikasi sistem informasi yang terkomputerisasi sehingga dapat memperbaiki kinerja perusahaan khususnya bagian Administrasi.

2. Proses dalam penilaian kinerja karyawan lebih efisien, tepat dan akurat.

3. Sebaiknya untuk data-data yang akan digunakan untuk rekapitulasi perhitungan penilaian kinerja karyawan tidak hanya di simpan di lemari arsip, namun bisa disimpan di hard disk agar tidak sulit saat ingin dilakukan pengolahan data tersebut.

4. Mem-back up data-data agar tidak ada kesalahan ataupun kehilangan data.

\section{Entity Relationship Diagram (ERD)}

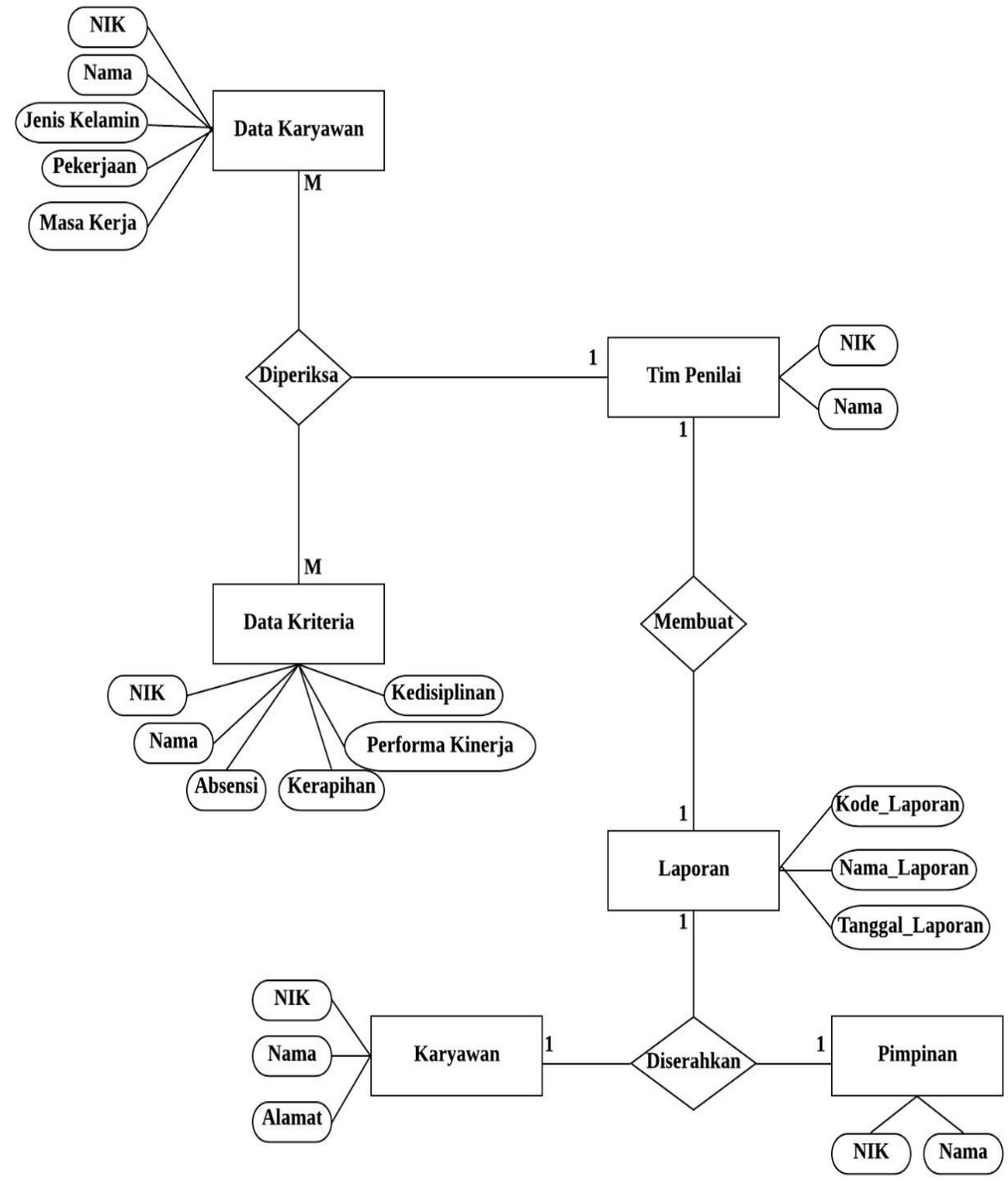

Gambar 1. Entity Relationship Diagram (ERD) 


\section{Tampilan Aplikasi}

Berikut ini hasil perancangan Sistem Penunjang Keputusan Penilaian Kinerja Karyawan.
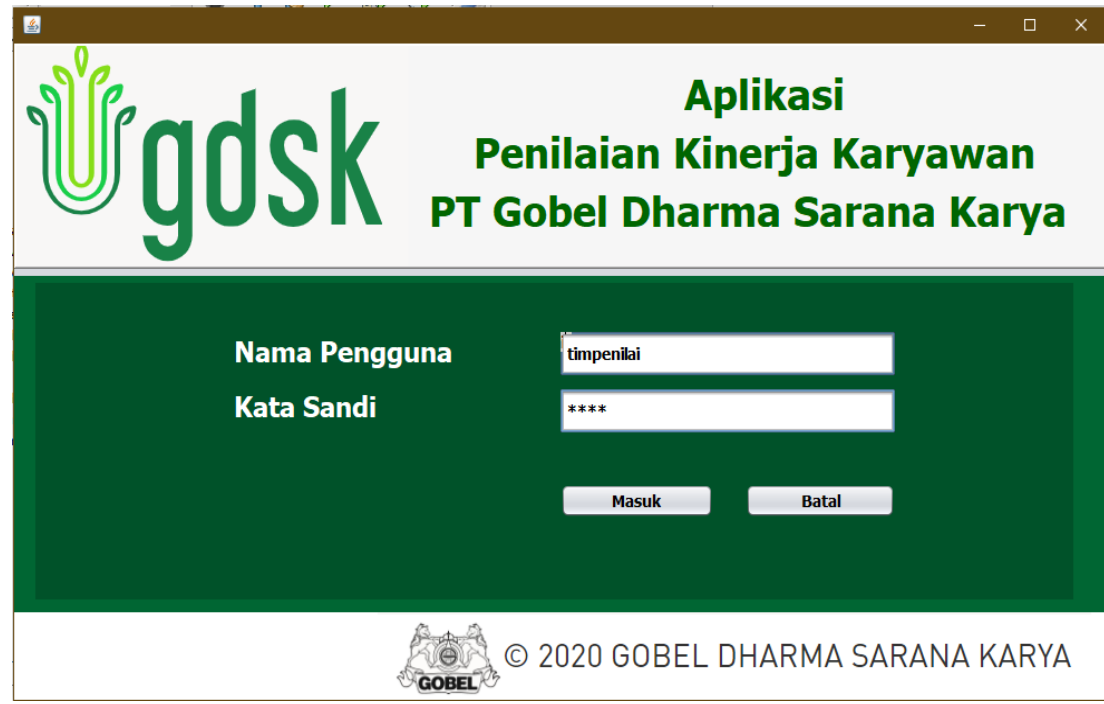

Gambar 2. Tampilan Menu Login

Pada gambar 2 diatas menampilkan form untuk login ke aplikasi.

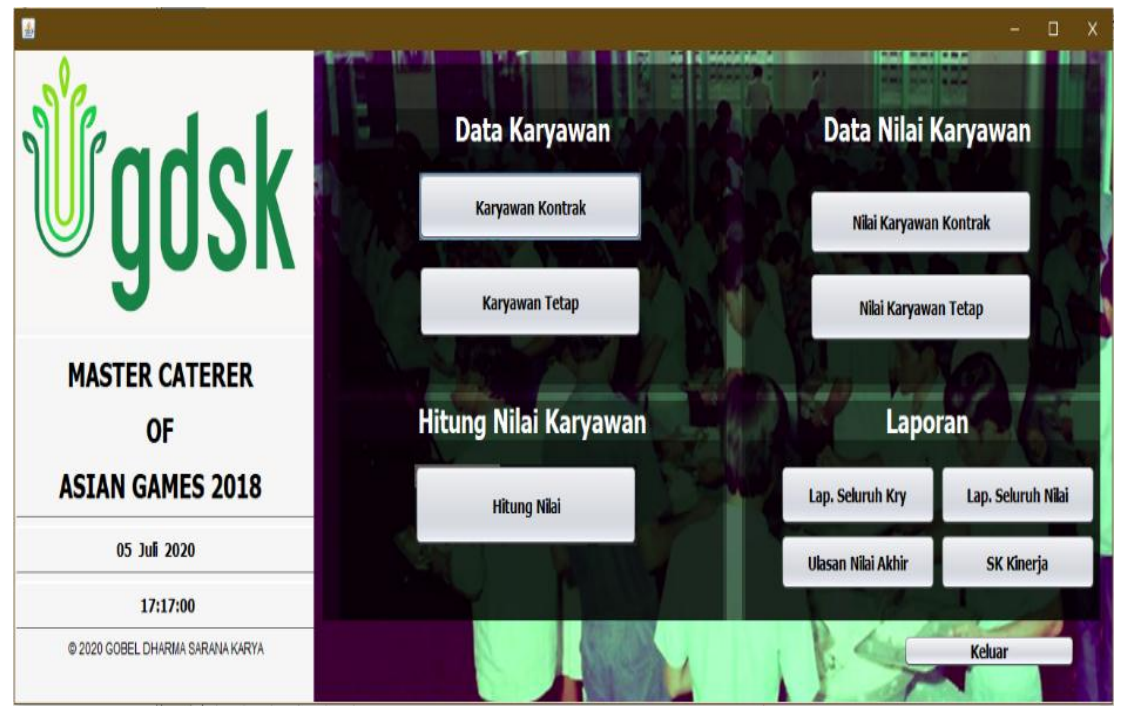

Gambar 3. Tampilan Layar Menu Utama 
Pada gambar 3 diatas menampilkan menu-menu untuk proses selanjutnya.

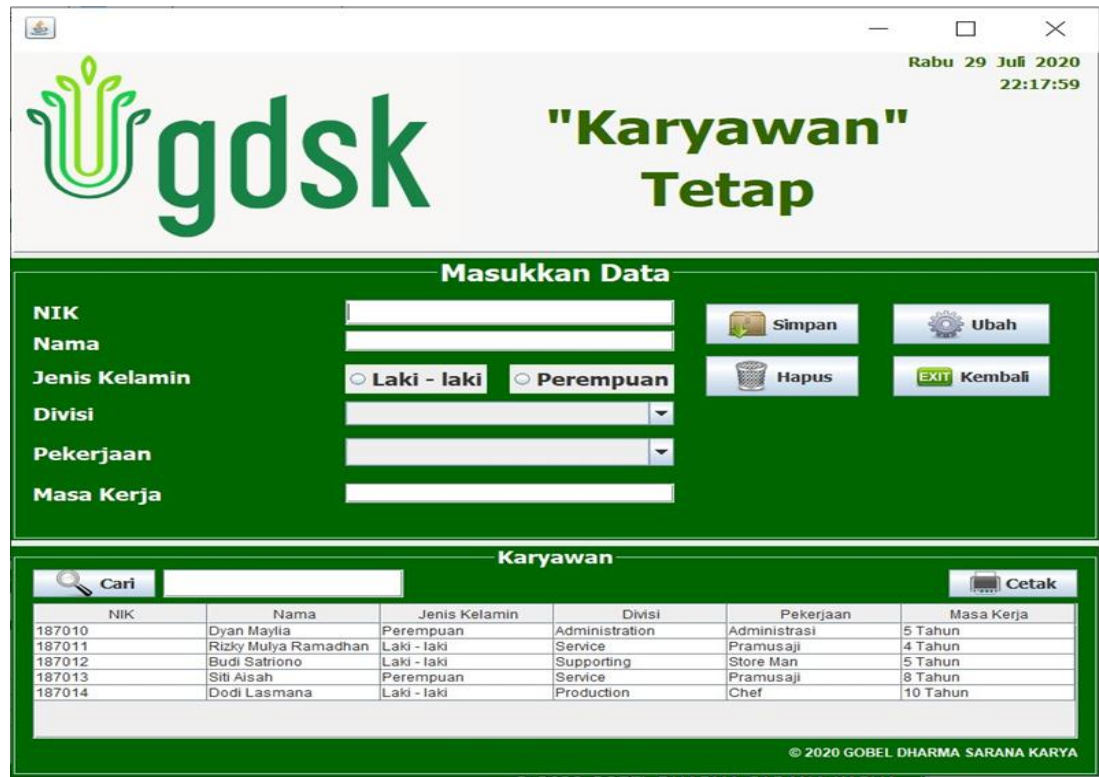

Gambar 4. Tampilan Data Karyawan Tetap

Pada layer ini terdapat kolom untuk memasukan data karyawan tetap dari nik, nama,jenis kelamin, divisi, pekerjaan, dan masa kerja.

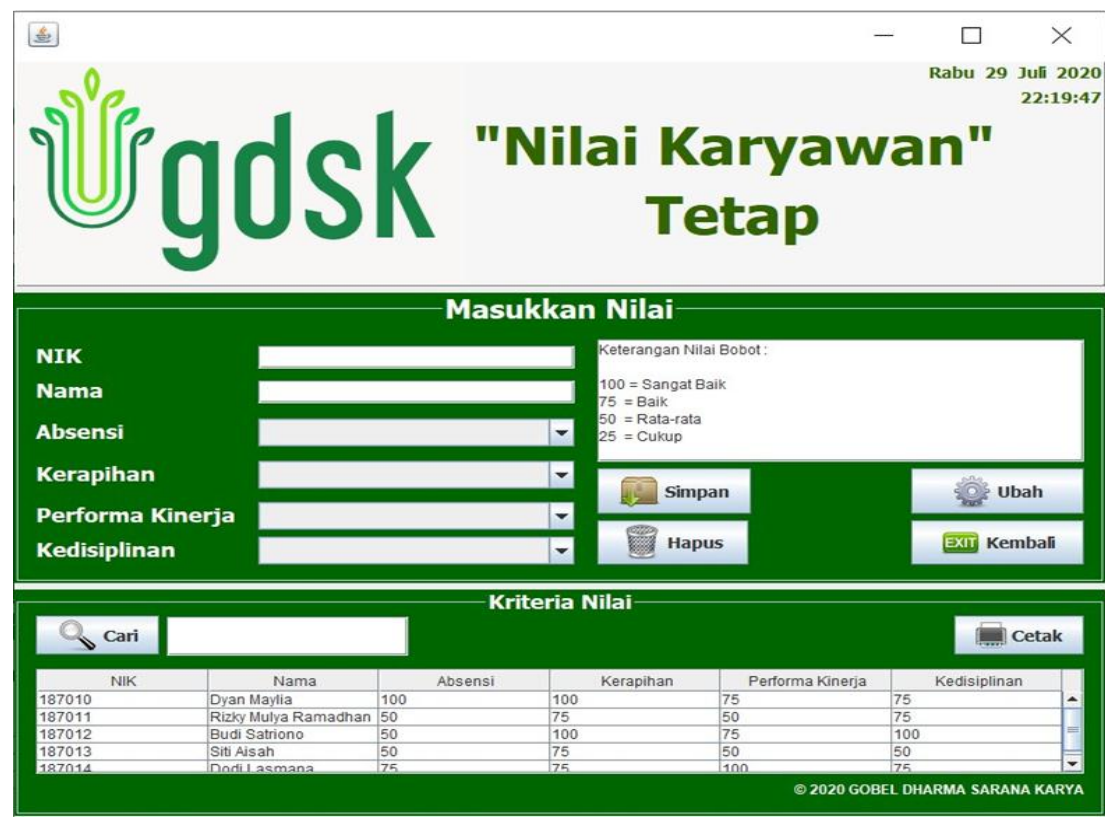

Gambar 5. Tampilan Layar Nilai Karyawan Tetap

Pada layer ini terdapat kolom untuk memasukan nilai karyawan tetap dari nik, nama, absensi (k1), kerapihan (k2), performa kinerja (k3) dan kedisiplinan (k4). 

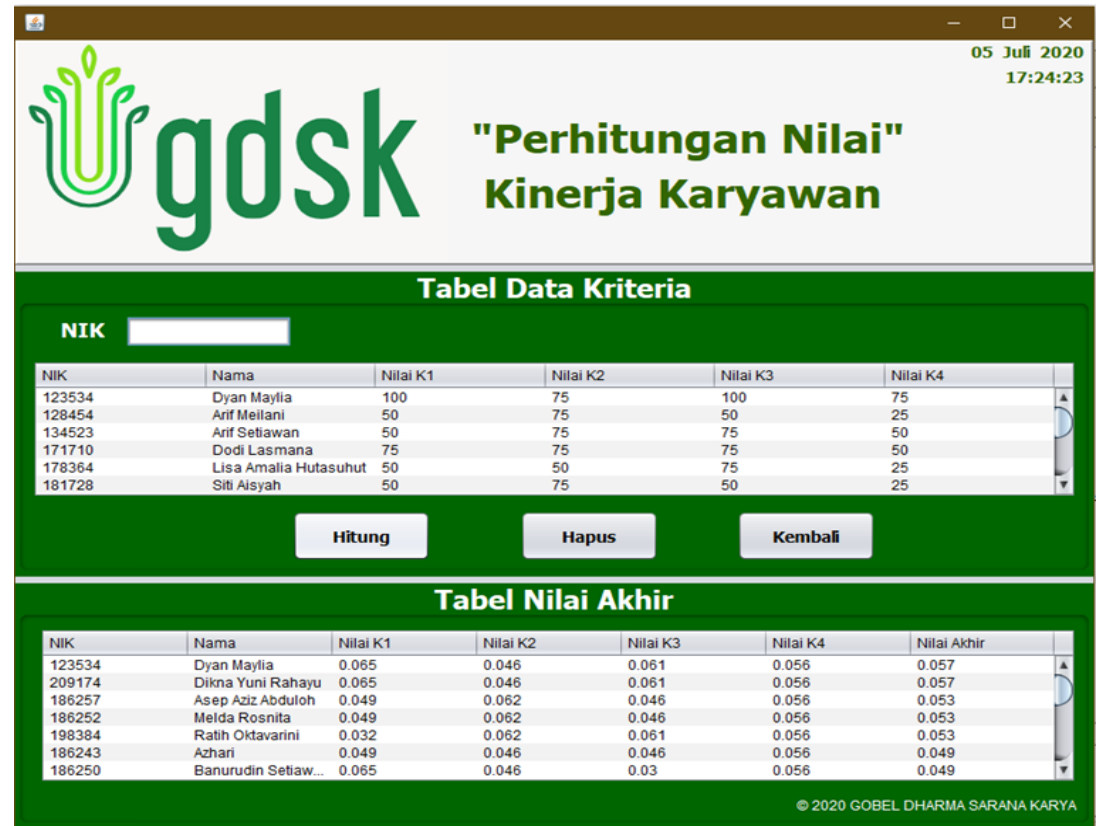

Gambar 6. Tampilan Perhitungan Nilai Kriteria

Pada layer ini terdapat data hasil dari perhitungan nilai kriteria yang telah di masukkan dan telah di urutkan berdasarkan nilai akhir yang paling tinggi.

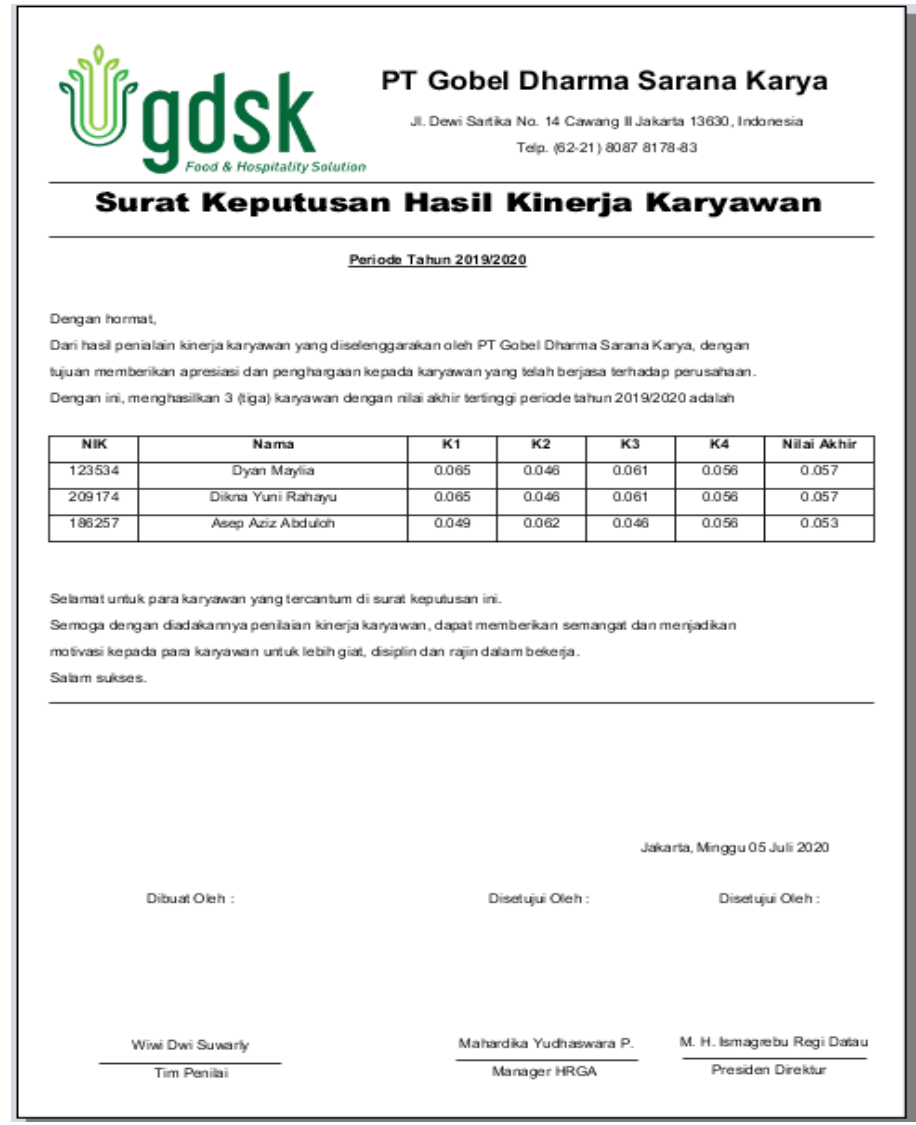

Gambar 7. Surat Keputusan Penilaian Kinerja Karyawan 
Tampilan output laporan berupa surat keputusan yang siap dicetak, hasil dari data perhitungan nilai kriteria yang telah di urutkan berdasarkan dan diambil 3 (tiga) nilai akhir tertinggi.

\section{SIMPULAN}

Berdasarkan Analisa yang telah dilakukan peneliti, maka Perancangan Sistem Penunjang Keputusan Penilaian Kinerja Karyawan dengan Metode AHP Berbasi Java (Studi kasus di PT Gobel Dharma Sarana Karya (GDSK)) yang dirancang peneliti dapat diterapkan dan merupakan salah satu solusi yang tepat bagi perusahaan ini. Sehingga dapat diambil simpulan yaitu Sistem Penunjang Keputusan Penilaian Kinerja Karyawan dirancang dan dibangun berdasarkan penelitian yang telah dilakukan dan menghasilkan suatu sistem yang bertujuan untuk memberikan rekomendasi penilaian kinerja bagi karyawan, sehingga menghasilkan alternatif solusi kegiatan penilaian kinerja karyawan yang mengefesienkan waktu dan keamanan data. Dan dengan adanya aplikasi ini memungkinan untuk terjadinya sistem menjadi lebih efektif, cepat, terkonsep dan up to date dalam pengolahan datanya.

\section{DAFTAR PUSTAKA}

[1] Jogiyanto, Analisis \& Desain Sistem Informasi. Yogyakarta: Andi Offset, 2013.

[2] A. Susanto, Sistem Informasi Akutansi. Bandung: Lingga Jaya, 2013.

[3] Subhan, "Pengertian Perancangan Sistem Informasi," 07/2012. 2012.

[4] I. Setiadi, "Sistem Pendukung Keputusan Pemilihan Mobil Bekas Dengan Metode AHP dan SAW Pada Nava Sukses Motor,” J. String, vol. 3, no. 3, pp. 247-257, 2019.

[5] Yakub, Pengantar Sistem Informasi. Yogyakarta: Graha Ilmu, 2012.

[6] Rosa dan Shalahuddin, Rekayasa Perangkat Lunak (Terstrukur dan Berorientasi Objek). 2016.

[7] H. Nurdiyanto and H. Meilia, "Sistem Pendukung Keputusan Penentuan Prioritas Pengembangan Industri Kecil Dan Menengah Di Lampung Tengah Menggunakan Analitical Hierarchy Process (Ahp)," Semnasteknomedia Online, vol. 4, no. 1, pp. 3.3-37, 2016.

[8] D. R. Sari, A. P. Windarto, D. Hartama, and S. Solikhun, "Decision Support System for Thesis Graduation Recommendation Using AHP-TOPSIS Method,” J. Teknol. dan Sist. Komput., vol. 6, no. 1, pp. 1-6, 2018. 